\title{
Balanço Eletrolítico em dietas com proteína reduzida para codornas japonesas no primeiro ciclo de produção
}

\section{Electrolyte Balance in reduced protein diets for Japanese quail in the first production cycle}

\author{
Ladyanne Raia Rodrigues ${ }^{1}$, Dermeval Araújo Furtado ${ }^{2}$, Fernando Guilherme Perazzo Costa ${ }^{3}$, José Wallace Barbosa do \\ Nascimento $^{4}$
}

\begin{abstract}
RESUMO: Determinar os índices produtivos e os valores de qualidade dos ovos de codornas japonesas na fase de postura foi o objetivo primordial deste trabalho, no qual, se utilizaram 288 aves, distribuídas no delineamento em blocos casualizados, com seis tratamentos e seis repetições de oito aves cada. Avaliaram-se os índices produtivos e os índices qualitativos em função dos níveis de balanço eletrolítico. Os resultados que apresentaram efeito significativo foi consumo de ração, consumo de água, produção, peso e massa de ovo, peso de gema e casca, percentagens de albúmen, gema e casca e a coloração de gema. Quanto à conversão alimentar tanto por massa quanto por dúzia de ovos não foi observada diferença estatística. O balanço eletrolítico não interferiu na produção das aves.
\end{abstract}

Palavras-chave: aminoácidos, proteína bruta, eletrólitos

\begin{abstract}
To determine the production rates and the values of egg quality of Japanese quails posture was the primary objective of this study, in which 288 birds were used, distributed in a randomized block design with six treatments and six replicates of eight birds each. Evaluated the production indices and qualitative indices according to the level of electrolyte balance. The results showed that significant effects were feed intake, water intake, output, weight, and egg mass, yolk and shell weight, percentage of albumen, yolk and shell and yolk color. As for the food conversion by both mass and per dozen eggs no statistical difference was observed. The electrolyte balance did not affect the production of poultry.
\end{abstract}

Keywords: amino acids, protein, electrolytes

\footnotetext{
*Autor para correspondência

Recebido para publicação em 10/11/2014; aprovado em 10/07/2015

${ }^{1}$ Zootecnista, Doutoranda no Programa de Pós graduação em Engenharia Agrícola - UFCG - Universidade Federal de Campina Grande, Caixa Postal: 58401 755, Campina Grande - PB. E-mail: ladyannezootecnia@hotmail.com,

${ }^{2}$ Zootecnista. D. Sc., Professor do Departamento de Engenharia Agrícola - UFCG - Universidade Federal de Campina Grande, Caixa Postal: 10078, 58429140, Campina Grande-PB. E-mail: dermeval@ deag.ufcg.edu.br,

${ }^{3}$ Zootecnista, D. Sc., Professor do Departamento de Zootecnia - UFPB - Universidade Federal da Paraíba, Caixa Postal: 58397-000, Areia - PB. E-mail: fperazzo@cca.ufpb.br

${ }^{4}$ Eng. Agr. D. Sc., Professor do Departamento de Engenharia Agrícola - UFCG - Universidade Federal de Campina Grande, Caixa Postal: 10078, 58429-140, Campina Grande - PB. E-mail: wallace@ deag.ufcg.edu.br
} 


\section{INTRODUÇÃO}

A produção de ovos aumenta a cada ano e, conseqüentemente, a busca para seu aprimoramento e novas tecnologias, sendo de fundamental importância o estudo da nutrição para se obter um produto final com qualidade (CRUZ et al., 2011).

A coturnicultura é uma atividade avícola em expansão, responsável pela geração de emprego e renda em todos os níveis de sua cadeia produtiva, sendo seus principais produtos o ovo e a carne, que são fontes de proteína animal de alto valor biológico (MOURA et al., 2010), destacando-se também na criação, a precocidade e alta taxa de postura das aves e o pequeno espaço para produção (GUIMARÃES et al., 2014).

Para que a produção, produtividade e a qualidade dos produtos sejam maximizadas, as aves devem ser bem alimentadas e criadas em instalações apropriadas e equipadas, possibilitando que as linhagens de matrizes exteriorizem a produção.

O ovo de codorna é um alimento completo e equilibrado em nutrientes, de baixo valor econômico, sendo uma fonte confiável de proteínas, lipídeos, aminoácidos essenciais, vitaminas e minerais (SEIBEL et al., 2010), com variações no seu tamanho, peso e composição química; seu tamanho é influenciado pela genética, nutrição, manejo, densidade de alojamento e condições ambientais (MOURA et al., 2010).

À medida que o conhecimento em nutrição evolui (SILVA et al., 2012), as dietas vão sendo formuladas com custo mínimo e máximo retorno econômico, sendo que a alimentação afeta os custos de produção das codornas desde a base, a indústria do melhoramento genético, até o topo da cadeia produtiva, ou seja, os abatedouros e frigoríficos.

No entanto, a manipulação do balanço eletrolítico dietético tem sido proposta como uma forma de melhorar o desempenho das aves alimentadas com dietas de baixa proteína bruta (OLIVEIRA et al., 2012).

Devido aos avanços da genética desta espécie, pesquisas foram realizadas a fim de estabelecer e atualizar constantemente os níveis adequados de nutrientes da dieta, visando à melhoria constante na taxa de produção das aves (COSTA et al., 2011), sendo a determinação dos níveis ideais de sódio, cloro e potássio para cada ciclo de produção da ave de grande importância, uma vez que estes eletrólitos desempenham um papel importante em vários processos fisiológicos, como a manutenção da pressão osmótica, síntese de proteínas teciduais, manutenção intra e extracelular homeostase, a manutenção do potencial elétrico da membrana celular, a homeostase ácido-base, assim como o funcionamento da enzima e dos nervos (OLIVEIRA et al., 2012).

Nesse sentido, o balanço eletrolítico (BE) da ração possui ligação direta com o equilíbrio ácido-básico interno do animal. Portanto, ao se variar o conteúdo protéico da ração (MINAFRA et al., 2009), torna-se necessário ajustar o balanço eletrolítico da dieta.

Diante do exposto, esta pesquisa teve como objetivo avaliar o balanço eletrolítico em dietas com redução de proteínas para codornas japonesas em produção.

\section{MATERIAL E MÉTODOS}

O experimento foi conduzido no Módulo de Avicultura do Centro de Ciências Agrárias do Departamento de Zootecnia da Universidade Federal da Paraíba, localizada no município de Areia, PB, inserida no brejo paraibano. De acordo com a classificação de Koppen, o clima da região é As', caracterizado como tropical quente-úmido, com chuvas de outono-inverno e temperaturas entre $15^{\circ}$ e $29^{\circ}$, com média anual de precipitação em torno $1800 \mathrm{~mm}$, com latitude $-06^{\circ}$ $57^{\prime} 48^{\prime}$ e longitude $-35^{\circ} 41^{\prime} 30^{\prime \prime}$ e altitude de $618 \mathrm{~m}$.

O período experimental foi de 84 dias, divididos em quatro períodos de 21 dias. Foram utilizadas 288 codornas japonesas (Cotornix cotornix japônica) com 18 semanas de idade. Utilizaram-se seis dietas experimentais. O tratamento 1 (T1) foi constituído de uma ração controle conforme a exigência do animal (NRC, 2004) à base de milho e farelo de soja suplementada com DL-metionina e colina. Para compor os tratamentos de 2 a 6 , a ração basal foi suplementada com diferentes níveis de aminoácido, de forma a obter seis níveis de balanço eletrolítico $(166,54,153,47,139,63,139,63$ 117,13 e 166,49). As dietas experimentais estão apresentadas na Tabela 1.

As codornas foram alojadas em baterias de gaiolas de arame galvanizado com dimensões de 33 × 33 x $14 \mathrm{~cm}$, cada uma composta por cinco gaiolas. Os comedouros eram tipo calha, nos quais as codornas receberam ração balanceada e os bebedouros eram adaptados com garrafas pets, nos quais as codornas receberam água (deionizada), ambos ad libitum, sendo a ração distribuída de forma manual duas vezes ao dia. Durante a fase de produção, os ovos foram coletados diariamente, às $8 \mathrm{~h}$, sendo anotados em fichas apropriadas: freqüência de postura, ovos íntegros, ovos quebrados, ovos trincados, ovos com casca fina, ovos sem casca, ovos deformados e qualquer outra anormalidade.

Nas variáveis quantitativas o consumo de ração ( $g$ ave $^{-1} \mathrm{~d}^{-1}$ ) foi calculado pela diferença de peso entre a quantidade fornecida e as sobras existentes no comedouro, sendo o resultado dividido pelo número de aves existentes em cada gaiola no final de cada fase experimental. Da mesma forma, o consumo de água foi calculado pelo somatório da água fornecida menos o somatório da água descartada na lavagem dos bebedouros e a sobra de água ao final dos períodos experimentais, medidos em proveta graduada. O ganho de peso das aves foi determinado através da diferença entre o peso inicial e o peso final das aves em cada período experimental. A conversão alimentar por massa de ovo foi calculada através da relação entre o consumo de ração e massa de ovo produzida. A conversão por dúzia de ovos foi obtida pelo produto entre o consumo médio de ração e a dúzia de ovos produzidos.

Na produção dos ovos (ovo/ ave $\left.{ }^{-1} \mathrm{~d}^{-1}\right)$ a coleta foi realizada diariamente, duas vezes ao dia pela manhã e a tarde, e a produção média dos ovos (PR) foi obtida dividindo-se o total de ovos produzidos pelo número de aves, corrigindo sempre pela mortalidade. O peso médio dos ovos $(\mathrm{g})$ foi calculado pela divisão do peso total pelo número de ovos. Os cálculos da massa de ovo foram realizados pelo produto da produção de ovos e do peso médio dos ovos por parcela. 
Tabela 01 - Composição percentual e nutricional das dietas

\begin{tabular}{|c|c|c|c|c|c|c|}
\hline Ingredientes & T1 & $\mathbf{T} 2$ & T3 & T4 & T5 & T6 \\
\hline Milho & 49,324 & 52,236 & 55,709 & 55,683 & 63,715 & 63,284 \\
\hline Farelo de Soja $45 \%$ & 39,183 & 36,720 & 33,739 & 33,742 & 25,370 & 25,370 \\
\hline Calcário & 7,0743 & 7,0801 & 7,0871 & 7,0871 & 7,1043 & 7,1043 \\
\hline Óleo de Soja & 2,6806 & 2,1570 & 1,5052 & 1,4942 & 1,1340 & 0,9650 \\
\hline Fosfato Bicálcico & 0,9225 & 0,9339 & 0,9479 & 0,9480 & 0,9925 & 0,9925 \\
\hline Sal & 0,5348 & 0,5345 & 0,5343 & 0,5343 & 0,5342 & 0,5342 \\
\hline Metionina & 0,1100 & 0,1280 & 0,1498 & 0,1499 & 0,2153 & 0,2153 \\
\hline Colina & 0,0700 & 0,0700 & 0,0700 & 0,0700 & 0,0700 & 0,0700 \\
\hline Vitamina & 0,0500 & 0,0500 & 0,0500 & 0,0500 & 0,0500 & 0,0500 \\
\hline Mineral & 0,0500 & 0,0500 & 0,0500 & 0,0500 & 0,0500 & 0,0500 \\
\hline Isoleucina & & 0,0396 & 0,0876 & 0,0876 & 0,2257 & 0,2257 \\
\hline Lisina & & & 0,0690 & 0,0689 & 0,2652 & 0,2652 \\
\hline Valina & & & & 0,0334 & 0,1668 & 0,1668 \\
\hline Treonina & & & & & 0,1064 & 0,1064 \\
\hline L-Arginina & & & & & & 0,2546 \\
\hline Inerte & & & & & & 0,2265 \\
\hline Carbonato de $\mathrm{K}$ & & & & & & 0,1187 \\
\hline Total & 100,00 & 100,00 & 100,00 & 100,00 & 100,00 & 100,00 \\
\hline \multicolumn{7}{|l|}{ Composição Calculada } \\
\hline Proteína Bruta & 20,000 & 17,000 & 17,000 & 17,000 & 17,000 & 17,000 \\
\hline Cálcio & 3,0500 & 3,0500 & 3,0500 & 3,0500 & 3,0500 & 3,0500 \\
\hline Fósforo Disponível & 0,2800 & 0,2800 & 0,2800 & 0,2800 & 0,2800 & 0,2800 \\
\hline E. Met. Aves & 2800,0 & 2800,0 & 2800,0 & 2800,0 & 2800,0 & 2800,0 \\
\hline Arg Dig. Aves & 1,4111 & 1,3428 & 1,2600 & 1,2600 & 1,2600 & 1,2600 \\
\hline Ile Dig. Aves & 0,8700 & 0,8700 & 0,8700 & 0,8700 & 0,8700 & 0,8700 \\
\hline Lys Dig. Aves & 1,0869 & 1,0300 & 1,0300 & 1,0300 & 1,0300 & 1,0300 \\
\hline Met Dig. Aves & 0,4135 & 0,4216 & 0,4315 & 0,4316 & 0,4614 & 0,4614 \\
\hline M+C Dig. Aves & 0,7000 & 0,7000 & 0,7000 & 0,7000 & 0,7000 & 0,7000 \\
\hline Thr Dig. Aves & 0,7415 & 0,7105 & 0,6728 & 0,6727 & 0,6700 & 0,6700 \\
\hline Trp Dig. Aves & 0,2484 & 0,2364 & 0,2218 & 0,2218 & 0,1800 & 0,1800 \\
\hline Val Dig. Aves & 0,9196 & 0,8824 & 0,8821 & 0,8700 & 0,8700 & 0,8700 \\
\hline Sódio & 0,2300 & 0,2300 & 0,2300 & 0,2300 & 0,2300 & 0,2300 \\
\hline Cloro & 0,3630 & 0,3631 & 0,3632 & 0,3632 & 0,3632 & 0,3632 \\
\hline Potássio & 0,6600 & 0,6090 & 0,5550 & 0,5550 & 0,4670 & 0,6600 \\
\hline Balanço Eletrolítico & 166,54 & 153,47 & 139,63 & 139,63 & 117,13 & 166,49 \\
\hline
\end{tabular}

${ }^{1}$ Premix mineral por kg de ração: Mn, 60 g; Fe, 80 g; Zn, 50 g; Cu, 10 g; Co, 2 g; I, 1 g; e veículo q.s.p., 500 g. ${ }^{2}$ Premix vitamínico (Concentração/kg): Vit. A - 15.000.000 Ul, Vit. D - 1.500.000 Ul, Vit. E - 15.000 Ul, Vit.B - 2,0 g, it.B ${ }_{2}-4,0$ g, Vit B6 - 3,0 g, Vit.B 12 - 0,015 g, Ácido nicotínico - 25 g, Ácido pantotênico- $10 \mathrm{~g}$, Vit.K $\mathrm{K}_{3}-3,0 \mathrm{~g}$, Ácido fólico- $1,0 \mathrm{~g}$, Selênio - $250 \mathrm{mg}$, e veículo. q.s.p. - $1.000 \mathrm{~g}$. ${ }^{3}$ Etoxiquim $-10 \mathrm{~g}$, e veículo q.s.p. $-1.000 \mathrm{~g}$. ${ }^{4}$ Areia lavada

Para a análise da qualidade dos ovos, os ovos dos últimos três dias de cada período experimental foram coletados manualmente, acondicionados em bandeja, sempre no mesmo horário $(8 \mathrm{~h})$ e em seguida transportados para o Laboratório do Departamento de Zootecnia da Universidade Federal da Paraíba (UFPB), onde foram identificados de acordo com cada tratamento e posteriormente realizadas as pesagens, utilizando-se balança de precisão 0,001. As variáveis mensuradas foram: peso do albúmen (PA), peso de gema (PG), peso de casca (PC), percentagem de albúmen $(\% \mathrm{~A})$, percentagem de gema $(\% \mathrm{G})$, percentagem de casca (\%C), pigmentação (PIG), espessura de casca (EC) e gravidade específica (GE).

Do total de ovos produzidos por repetição, quatro unidades foram selecionadas para determinação dos pesos e das porcentagens de gema, albúmen e casca. Após a separação manual desses componentes, as cascas foram mantidas em estufa com ventilação forçada a $105^{\circ} \mathrm{C}$ por 4 horas. As porcentagens de gema, albúmen e casca foram obtidas dividindo-se o peso de cada um destes componentes pelo peso do ovo; multiplicando-se o resultado por 100 .
A gravidade específica foi determinada pelo método de flutuação salina, conforme metodologia descrita por (HAMILTOM, 1982). Ao final de cada período experimental, foram selecionadas amostras representativas de dois ovos por parcela e, em seguida, foram feitas imersões dos ovos em diversas soluções salinas com os devidos ajustes para o volume de 25 litros de água com densidades que variavam de 1,060 a 1,100 com intervalo de 0,025 . Os ovos foram colocados nos baldes com as soluções, da menor para a maior densidade, e retirados ao flutuarem registrando-se os valores das densidades correspondentes às soluções dos recipientes. Antes de cada avaliação, as densidades foram conferidas com densímetro de petróleo. A pigmentação foi obtida através do leque calorimétrico ROCHE, numa escala de valores de 1 a 15 (do amarelo claro à cor de abóbora respectivamente). A espessura da casca foi obtida através da utilização de micrômetro digital Mitutoyo de 0-25 mm, com precisão de $0,001 \mathrm{~mm}$, após serem secas em estufa.

$\mathrm{Na}$ análise estatística foi utilizado o delineamento em blocos casualizados (DBC), constituído de seis tratamentos e seis repetições com oito aves por unidade experimental para cada período de 21 dias e dois horários ( 8 e 16 h). Os dados 
foram analisados utilizando-se o programa Sistema para Análises Estatísticas e Genética (SAEG, 2005). As médias foram comparadas pelo teste de Tukey adotando-se o nível de $5 \%$ de probabilidade respectivamente.

\section{RESULTADOS E DISCUSSÃO}

Observa-se efeito significativo $(\mathrm{p}<0,05)$ no consumo de ração, consumo de água, produção, peso e massa de ovo (Tabela 02) em relação aos níveis de balanço eletrolítico da dieta. No que se referiu ao consumo de ração, observa-se que as alojadas nos tratamentos 2 e 4 apresentaram os maiores consumos $\left(30,66\right.$ e $\left.31,54 \mathrm{~g} \mathrm{dia}^{-1}\right)$ respectivamente, diferindo do tratamento $1\left(27,23 \mathrm{gr} \mathrm{dia}^{-1}\right)$, mas não diferindo significativamente dos demais tratamentos. Em relação aos tratamentos 3,5 e 6 não diferença significativa entre os mesmos, justificando que a adição do aminoácido valina nos tratamentos 4, 5 e 6, não interferiu sobre o consumo das aves, uma vez que este aminoácido pode causar efeito na produção e no desempenho das aves.

Tabela 02. Consumo de ração $(\mathrm{CR})$, consumo de água $\left(\mathrm{CH}_{2} \mathrm{O}\right)$, produção de ovos $(\mathrm{PR})$, peso médio de ovos (PO), massa de ovo (MO), conversão alimentar por massa (CAMO) e por dúzia de ovo (CADZ) de codornas japonesas, de acordo com os níveis de balanço eletrolítico da dieta

\begin{tabular}{cccccccc}
\hline TRAT. & $\mathrm{CRg} / \mathrm{dia}$ & $\mathrm{CH}_{2} \mathrm{O}$ & $\mathrm{PR}(\%)$ & $\mathrm{PO}(\mathrm{g})$ & $\mathrm{MO}(\mathrm{g})$ & $\mathrm{CAMOkg} / \mathrm{g}$ & $\mathrm{CADZkg} / \mathrm{dz}$ \\
\hline 1 & $27,20 \mathrm{~b}$ & $63,13 \mathrm{ab}$ & $75,8 \mathrm{~b}$ & $11,50 \mathrm{a}$ & $9,1 \mathrm{~b}$ & $2,29 \mathrm{a}$ & $0,34 \mathrm{a}$ \\
2 & $30,66 \mathrm{a}$ & $65,64 \mathrm{ab}$ & $84,6 \mathrm{ab}$ & $11,20 \mathrm{ab}$ & $10,3 \mathrm{a}$ & $2,34 \mathrm{a}$ & $0,34 \mathrm{a}$ \\
3 & $29,68 \mathrm{ab}$ & $67,07 \mathrm{ab}$ & $78,7 \mathrm{ab}$ & $11,20 \mathrm{ab}$ & $10,5 \mathrm{a}$ & $2,36 \mathrm{a}$ & $0,33 \mathrm{a}$ \\
4 & $31,54 \mathrm{a}$ & $70,63 \mathrm{a}$ & $82,3 \mathrm{ab}$ & $11,64 \mathrm{a}$ & $9,7 \mathrm{a}$ & $2,61 \mathrm{a}$ & $0,36 \mathrm{a}$ \\
5 & $29,43 \mathrm{ab}$ & $58,06 \mathrm{~b}$ & $79,8 \mathrm{ab}$ & $11,15 \mathrm{~b}$ & $9,1 \mathrm{~b}$ & $2,31 \mathrm{a}$ & $0,32 \mathrm{a}$ \\
6 & $29,37 \mathrm{ab}$ & $58,16 \mathrm{~b}$ & $85,3 \mathrm{a}$ & $11,64 \mathrm{a}$ & $9,1 \mathrm{~b}$ & $2,47 \mathrm{a}$ & $0,33 \mathrm{a}$ \\
\hline Média & 29,55 & 64,38 & 81,53 & 11,38 & 9,63 & 2,35 & 0,34 \\
CV $(\%)$ & 3,67 & 6,77 & 3,55 & 4,68 & 3,55 & 5,08 & 4,24 \\
\hline
\end{tabular}

Médias seguidas de mesma letra, na coluna, não diferiram estatisticamente pelo teste de Tukey $(\mathrm{P}<0,05)$.

O consumo médio diário de ração por ave foi de 29,55 $\mathrm{g} \mathrm{dia}^{-1}$, demonstrando que as dietas responderam satisfatoriamente aos tratamentos, corroborando com a literatura, que relata o consumo diário de codornas deve estar entre 25 a 35g/dia. Sucupira et al. (2007) observaram consumo médio de $22,45 \mathrm{~g} \mathrm{dia}^{-1}$, sendo esta diferença justificada pela diferença entre as dietas utilizadas. Um dos fatores que pode interferir no consumo é a temperatura, ou seja, com o aumento da temperatura ambiente as aves deixam de consumir alimento e passam a utilizar mecanismos para dissipar calor do corpo para o meio.

O maior consumo de água (Tabela 03) foi verificado nas aves que consumiram a ração referente ao tratamento quatro (70,63 mL/ave/dia), já o menor consumo foi verificado nas aves que consumiram a ração referente ao tratamento cinco $(58,06 \mathrm{~mL} / \mathrm{ave} / \mathrm{dia})$. Analisando o consumo médio de água $64,38 \mathrm{~mL} / a v e / d i a$, este pode ser considerado um alto consumo, discordando de (LIMA et al., 2011), que em trabalhos com codornas de postura na fase de crescimento e alimentadas com ração a base de sódio obtiveram consumo médio de $28,55 \mathrm{~mL} / \mathrm{ave} / \mathrm{dia}$, o que pode ser justificado pela temperatura do ar acima da ZCT, dificultando a dissipação de calor e causando estresse nas aves, fazendo com que as mesmas acionassem mecanismos fisiológicos como diminuição do consumo de ração e aumento no consumo de água, como também, pode ser justificado pela mudança no balanço eletrolítico.

Rodrigues et al. (2007) em trabalhando com níveis de exigências de sódio para codornas japonesas em crescimento no brejo paraibano, relatam que a utilização de água deionizada promove resultados mais confiáveis e próximos do real o que, sem dúvida, torna os trabalhos com garantia de resultados que promovam melhoria no desempenho das codornas. Raquel et al. (2010) em experimento com codornas italianas conduzido no estado do Ceará, observaram temperaturas ambiente mínima, máxima e umidade relativa médias de $28^{\circ} \mathrm{C}, 32^{\circ} \mathrm{C}$ e $86 \%$, respectivamente e observaram aumento na conversão alimentar e na ingestão de água.

O aumento da ingestão de alimento pelas aves está associado ao aumento da ingestão de água, no entanto, as aves consomem maior quantidade de água quando a temperatura ambiente aumenta, assim é importante que tenham acesso à quantidade suficiente de água com qualidade e temperatura adequadas, especialmente no período seco, uma vez que a capacidade de perda de calor corporal tem influencia direta no ganho de peso, produção de ovos e taxa de sobrevivência, além do consumo de água dobrar ou até triplicar durante os períodos de estresse calórico (GAMA, 2011).

Houve diferença significativa na produção de ovos apenas entre o tratamento um $(75,8 \%)$ e o tratamento seis $(85,3 \%)$, no qual tinha em sua composição uma redução de proteína bruta na ração e o maior nível de balanço eletrolítico (Tabela 4), indicando que as mesmas direcionaram grande parte dos nutrientes consumidos para produzir ovo. Santos et al. (2011) trabalhando com matrizes pesadas, obtiveram uma melhora significativa na produção de ovos após adicionar eletrólitos na ração. Analisando a média de produção de ovos, que foi de $81,53 \%$, observa-se que a mesma está de acordo com a média de produção de codornas no Brasil, semelhante aos valores relatados por (MORI et al., 2005), que obtiveram produção média de 82,27\% e (GUIMARÃES et al., 2014) que citam valores de produção superior e com menor consumo de nutrientes ao compararam a linhagem japonesa com a européia em duas estações do ano.

A média do peso dos ovos foi de $11,38 \mathrm{~g}$, semelhantes às relatadas por (UMIGI et al.,2012) que em trabalhos com codornas japonesas alimentadas com dietas suplementas com diferentes níveis de treonina, citam valores de peso de ovo de 11,3g e (GRAVENA et al. 2011), que em estudo com codornas japonesas suplementadas com minerais orgânicos, relatam que peso dos ovos variaram de 10,95 a $11,19 \mathrm{~g}$, sendo 
a temperatura ambiente registrada foi de $21,3{ }^{\circ} \mathrm{C}$ e a umidade relativa de $76,4 \%$.

A média geral de massa de ovos produzida foi de 9,63 g/ave/dia, sendo este valor semelhante ao encontrado por (COSTA et al., 2008), que trabalhando com codornas de corte, obtiveram um peso médio de 9,82 g/ave/dia. A conversão alimentar por massa e por dúzia de ovos não foram afetadas pelos diferentes níveis de balanço eletrolítico, ficando dentro da média considerada normal para codornas de postura e semelhantes aos valores citados por (COSTA et al., 2011).

Constatou-se efeito significativo $(\mathrm{P}<0,05)$ sobre as características de qualidade dos ovos, exceto para o peso de gema, o peso de casca, porcentagem de albúmen, porcentagem de gema, porcentagem de casca e pigmentação da gema (Tabela 03) entre os diferentes tratamentos estudados.

Os resultados para peso de albúmen e casca, estão coerentes com os obtidos por (MOURA et al., 2010), avaliando a qualidade de ovos de codornas japonesas alimentadas com dietas de diferentes densidades energéticas e criadas em ambiente com temperatura média de $24,4^{\circ} \mathrm{C}$, que encontraram valores próximos. Segundo (LIMA, 2011), existe uma relação direta entre a gravidade específica e o peso da casca.

Foi verificado o menor peso de gema no tratamento no qual tinha o menor nível de balanço eletrolítico, justificando que a adição de aminoácidos na ração promove resultados significantes na qualidade dos ovos.

A média geral do peso da gema observada neste experimento, foi de $4,14 \mathrm{~g}$ superior a reportada por (COSTA et al., 2008), que trabalhando com codornas de corte de dois grupos genéticos encontraram médias de $3,96 \mathrm{~g}$, justificando que a inclusão de diferentes níveis de balanço eletrolítico na dieta, interferem positivamente no peso da gema. Garcia et al. (2012), trabalhando com milheto na alimentação de codornas japonesas, encontraram média de 4,64g no peso da gema e, o aumento dos níveis de milheto na ração proporcionou diminuição no peso da gema.

Tabela 03. Peso de albúmen (PA), gema (PG), casca (PC), porcentagem de albúmen (\%A), gema (\%G), casca (\%C), pigmentação (PIG), espessura da casca (EC) e gravidade específica (GE) de codornas japonesas, de acordo com os níveis de balanço eletrolítico da dieta.

\begin{tabular}{cccccccccc}
\hline TRAT. & PA & PG & PC & \%ALB & $\% \mathrm{G}$ & $\% \mathrm{C}$ & PIG & EC & GE \\
\hline 1 & 6,35 & $4,34 \mathrm{a}$ & $0,73 \mathrm{ab}$ & $52,80 \mathrm{ab}$ & $35,75 \mathrm{a}$ & $6,13 \mathrm{ab}$ & $3,91 \mathrm{c}$ & 226,77 & 1,07 \\
2 & 6,13 & $4,21 \mathrm{ab}$ & $0,72 \mathrm{~b}$ & $49,84 \mathrm{~b}$ & $33,83 \mathrm{ab}$ & $5,88 \mathrm{a}$ & $4,22 \mathrm{bc}$ & 218,85 & 1,07 \\
3 & 6,27 & $3,93 \mathrm{c}$ & $0,77 \mathrm{a}$ & $51,39 \mathrm{~b}$ & $31,75 \mathrm{~b}$ & $6,32 \mathrm{ab}$ & $4,47 \mathrm{ab}$ & 225,55 & 1,07 \\
4 & 6,34 & $4,16 \mathrm{ab}$ & $0,74 \mathrm{ab}$ & $54,53 \mathrm{ab}$ & $36,03 \mathrm{a}$ & $6,40 \mathrm{ab}$ & $4,47 \mathrm{ab}$ & 222,20 & 1,07 \\
5 & 6,37 & $3,99 \mathrm{bc}$ & $0,74 \mathrm{ab}$ & $57,53 \mathrm{a}$ & $36,44 \mathrm{a}$ & $6,67 \mathrm{a}$ & $4,41 \mathrm{ab}$ & 216,68 & 1,07 \\
6 & 6,29 & $4,26 \mathrm{a}$ & $0,75 \mathrm{ab}$ & $54,05 \mathrm{ab}$ & $37,04 \mathrm{a}$ & $6,45 \mathrm{ab}$ & $4,70 \mathrm{a}$ & 222,76 & 1,07 \\
\hline Média & 6,3 & 4,14 & 0,75 & 53,34 & 35,1 & 6,31 & 4,36 & 222,12 & 1,07 \\
CV $(\%)$ & 5,44 & 3,09 & 5,74 & 2,4 & 4,23 & 2,93 & 4,23 & 3,08 & 0,05 \\
\hline
\end{tabular}

Médias seguidas de mesma letra, na coluna, não diferiram estatisticamente pelo teste de Tukey $(\mathrm{P}<0,05)$.

Os valores da presente pesquisa em relação à porcentagem de albúmen, percentagem de casca e espessura da casca corroboram com (GUIMARÃES et al., 2014), que em estudos com codornas no semiárido paraibano encontraram valores semelhantes para a mesma espécie, para o peso de casca observou-se valores superiores em comparação aos da referida pesquisa. Já (GRAVENA et al., 2011), em estudo com codornas japonesas suplementadas com diferentes níveis de selênio e zinco orgânico e (LAGANÁ et al., 2011) com métodos de debicagem e do tipo de bebedouro na qualidade de ovos de codornas japonesas, encontraram valores superiores para percentagem do albúmen e inferiores para percentagem da gema mas semelhantes para espessura e peso da casca aos do presente trabalho.

De acordo com (MARINHO, 2011), a diminuição da porcentagem de albúmen apresenta relação com o aumento do índice e porcentagem de gema, e ocorre devido à desnaturação da proteína ovomucina que resulta na migração da água do albúmen para gema, que acarreta aumento no peso da gema e interfere diretamente nos valores de porcentagem de albúmen, resultado que corrobora com os encontrados neste trabalho, uma vez que, o albúmen representa cerca de $55,74 \%$ do peso do ovo de codorna. No entanto (MAGALHÃES, 2012) afirmou que a composição da gema pode variar bastante de acordo com o tipo de alimentação oferecida às aves.

Houve diferença significativa no que se refere à pigmentação da gema (Tabela 4), onde os tratamentos que tinha a proteína reduzida $(17,0 \%)$ apresentaram maior valor para pigmentação da gema, podendo estar relacionado com a maior inclusão de milho na dieta, já que este ingrediente contribui bastante para a pigmentação. De acordo com (OLIVEIRA et al., 2007), a intensidade da cor da gema pode variar do amarelo ao laranja, decorrente da incorporação de xantofilas, principalmente luteína e zeaxantina presentes no milho, é dependente dos níveis de inclusão do milho amarelo nas rações de poedeiras.

De acordo com (MOURA, 2010), a coloração da gema é um critério de avaliação de qualidade pelo consumidor ou indústria. Entretanto, o ovo de codorna geralmente é consumido cozido e inteiro, ao contrário do ovo de galinha, que é submetido à cocção, fritura ou processamento pela indústria alimentícia. Isso torna a cor da gema do ovo de codorna um atributo de importância econômica primária e de grande relevância.

De acordo com os estudos na área da nutrição e com os avanços no conhecimento do metabolismo protéico e o surgimento de novos aminoácidos industriais produzidos em escala comercial tornam-se possível formular rações com níveis reduzidos de proteína bruta, pois possíveis deficiências em aminoácidos, em virtude da redução do nível protéico das rações, podem ser corrigidas com a inclusão desses aminoácidos. No entanto, (GOMIDE et al., 2011) relataram sobre a necessidade de se formular rações com o perfil de aminoácidos mais próximo da exigência do animal. Rodrigues 
(2009) cita serem poucos os estudos feitos para se determinar o BE de dietas para codornas japonesas.

\section{CONCLUSÕES}

As codornas alimentadas com $17 \%$ de proteína bruta e balanço eletrolítico de $139,63 \mathrm{mEq} / \mathrm{kg}$ de ração, na qual tinha a adição de valina em sua composição na dieta, proporcionou o melhor desempenho em comparação aos demais tratamentos.

\section{REFERÊNCIAS BIBLIOGRÁFICAS}

COSTA, C. H. R.; BARRETO, S. L. T.; FILHO, R. M. M.; ARAUJO, M. S.; UMIGI, R. T.; LIMA, H. J. A Avaliação do desempenho e da qualidade dos ovos de codornas de corte de dois grupos genéticos. Revista Brasileira de Zootecnia, v.37, p.1823-1828, 2008.

COSTA, F G. P.; RODRIGUES, L. R.; GOULART, C. C.; OLIVEIRA, C. F. S.; RODRIGUES, V. P.; SILVA, J. H. V. Nutritional potassium requirement for laying Japanese quails. Revista Brasileira de Zootecnia, v.40, p.2754-2759, 2011.

CRUZ, V. C.; FERNANDEZ, I. B. Effect of organic selenium and zinc on the performance and egg quality of Japanese quails. Revista Brasileira de Ciência Avícola, v.13, p.9195,2011

GAMA, N. M. S. Q. Qualidade química e bacteriológica da água utilizada na dessedentação de aves. $14^{\circ}$ Curso de sanidade Avícola Fort Dodge. Disponível em: http://www.fortdodge.com.br/14sanidade/pdf/16importa nciadaaguanaavicultura.pdf.Acesso em: 10/03/2011.

GARCIA, A. F. Q. M.; MURIKAMI, A. E.; MASSUDA, E. M.; URGNANI, F. J.; POTENÇA, A.; DUARTE, C. R. A.; Eyng, C. Milheto na alimentação de codornas japonesas. Revista. Brasileira Saúde Produção Animal, Salvador, v.13, n.1, p.150-159, 2012.

GOMIDE, E. M.; RODRIGUES, P. B.; BERTECHINI, A. G.; FREITAS, R. T. F.; FASSANI, E. J.; REIS, M. P.; RODRIGUES, N. E. B.; ALMEIDA, E. C. Rações com níveis reduzidos de proteína bruta, cálcio e fósforo com fitase e aminoácidos para frangos de corte. R. Bras. Zootec., v.40, n.11, p.2405-2414, 2011.

GRAVENA, R. A.; MARQUES, R. H.; PICARELLI, J.; SILVA, J. D. T.; ROCCON, J.; HADA, F. H.; QUEIROZ, S. A.; MORAES, V. M. B. Suplementação da dieta de codornas com minerais nas formas orgânicas sobre o desempenho e qualidade dos ovos. Arquivo Brasileiro de Medicina Veterinária e Zootecnia, v.63, p.1453-1460, 2011.

GUIMARÃES, M. C. C.; FURTADO, D. A.; NASCIMENTO, J. W. B.; TOTA, L. C. A.; SILVA, C. M.; LOPES, K. B. P. Efeito da estação do ano sobre o desempenho produtivo de codornas no semiárido paraibano. Revista Brasileira de Engenharia Agrícola e Ambiental, v.18, p.231-237, 2014.
HAMILTON, R.M.G. Methods and factors that affect the measurement of egg shell quality. Poultry Science, v.61, p.2022-2039, 1982 .

LAGANÁ, C.; PIZZOLANTE, C. C.;TOGASHI, C. K.; KAKIMOTO, S. K.; SALDANHA, E. S. P.B.; ÁLVARES, V. Influência de métodos de debicagem e do tipo de bebedouro no desempenho e na qualidade dos ovos de codornas japonesas. R. Bras. Zootec., v.40, n.6, p.1217-1221, 2011.

LIMA, R. C.; FREITAS, E. R.; RAQUEL, D. L.; SÁ, N. L.; LIMA, C. A. DE; PAIVA, A. C. Níveis de sódio para codornas japonesas na fase de crescimento. Revista Brasileira de Zootecnia, v.40, p.352-360, 2011.

MAGAlHÃES, A. P. C.; CURVELlo, F. A.; MORENZ, M. J.; Calixto, L. F.; Rezende, S. R. F. Qualidade de Ovos Comerciais de Acordo com a Integridade da Casca, Tipo de Embalagem e Tempo de Armazenamento. Rev. de Ciência da Vida, RJ, Edur, v. 32, n 2, p. 51-62, 2012.

MARINHO, A. L. Qualidade interna e externa de ovos de codornas japonesas armazenados em diferentes temperaturas e períodos de estocagem. Rio Largo: UFAL, 2011, 78 p. Dissertação de Mestrado.

MINAFRA, C. S.; MORAES, G. H. K.; LOPES, A. C. C.; JÚNIOR, C. O. L.; VIEITES, F. M.; REZENDE, C. S. M.; VIU, M. A. O. Balanço eletrolítico e proteico dietéticos sobre as aminotransferases hepáticas, renais e séricas e teores séricos de magnésio e cloro de frangos de corte. Ciência Animal Brasileira, v. 10, n. 2, p. 425437, 2009.

MÓRI, C.; GARCIA, E.A.; PAVAN, A.C.; PICCININ, A.; SCHERER, M.R.; PIZZOLANTE, C.C. Desempenho e qualidade dos ovos de codornas de quatro grupos genéticos. Revista Brasileira de Zootecnia, v.34, p.864$869,2005$.

MOURA, A.M.A.; FONSECA, J. B.; RABELO, C. B. V.; TAKATA F. N.; OLIVEIRA, N. E. T. Desempenho e qualidade do ovo de codornas japonesas alimentadas com rações contendo sorgo. Revista Brasileira de Zootecnia, v.39, p. 2697- 2702, 2010.

NATIONAL RESEARCH COUNCIL - NRC. Nutrient requirements of poultry. 9.ed. Washington, D.C.: National Academy of Sciences, 155p, 2004..

OLIVEIRA, B. L. Manejo em granjas automatizadas de codornas de postura comercial. In: Simpósio Internacional de Coturnicultura, 3, 2007. Lavras. Anais... Lavras: Núcleo de Estudos em Ciência e Tecnologia Avícolas, p.11-16, 2007.

OLIVEIRA, C. F.S.; COSTA, F. G. P.; SILVA, J. H. V.; GOULART, C. C.; SARAIVA, E. P.; GIVISIEZ, P. E. N.; LOBATO, G. B. V.; BEZERRA, R.M. Electrolyte balance in diets with reduced protein for semi-weighted 
laying hens in the second production cycle. R. Bras.

Zootec., v.41, n.7, p.1671-1675, 2012.

RAQUEL, D. L.; LIMA, R. C.; FREITAS, E. R.; SÁ, N. L.; XAVIER, R. P. S.; PAIVA, A. C. Níveis de cloro para codornas italianas destinadas à produção de carne. Acta Scientiarum. Animal Sciences Maringá, v. 32, p. 39-45, 2010.

RODRIGUES, V.P.; COSTA, F.G.P; SILVA, J.H.V.; GOULART, C.C.; LIMA, M.R.; FIGUEIREDO, D.F.; LIMA NETO, R.C. Exigências de sódio para codornas japonesas em crescimento de 24 a 40 dias de idade. In: simpósio internacional, congresso brasileiro de coturnicultura, 2004, Lavras. Anais... Lavras: Universidade Federal de Lavras, 2007.

RODRIGUES, V. P. Formulação de rações com base em aminoácidos digestíveis para codornas japonesas. Areia: UFPB, 2009. Dissertação de Mestrado.

SAEG: Sistema para Análises Estatísticas e Genéticas versão 9.0. Viçosa: UFV, 2005.

SANTOS, T. T.; SANTOS, S. A.; BORGES, S. A.; SILVA, A. V. F.; MAIORKA, A. Aplicação estratégica do balanço eletrolítico em dietas para matrizes pesadas. Ciência Rural, Santa Maria, v.41, p.895-900, mai, 2011.

SEIBEL, N. F.; SCHOFFEN, D. B.; QUEIROZ, M. I.; SOARES, L. A. S Caracterização sensorial de ovos de codornas alimentadas com dietas modificadas. Ciênc. Tecnol. Aliment., Campinas, v. 30, n. 4, p.884-889, 2010.

SILVA, J. H. V.; JORDÃO FILHO, J.; COSTA, F. G. P.; LACERDA, P. B.; VARGAS, D. G. V.; LIMA, M. R. Exigências nutricionais de codornas. Revista Brasileira de Saúde e Produção Animal, v.13, p.775-790, 2012.

SUCUPIRA, F. S.; FUENTES, M. F. F.; FREITS, E. R.; BRAZ, N. de M. Alimentação de codornas de postura com rações contendo levedura de cana-de-açúcar. Ciência Rural, Santa Maria, v.37, p.528-532, 2007.

UMIGI, R. T.; BARRETO, S. L. T.; REIS, R. S.; MESQUITA FILHO, R. M. ARAÚJO, M. S. Níveis de treonina digestível para codornas japonesas na fase de produção. Arquivo Brasileiro de Medicina Veterinária e Zootecnia, v.64, p.658-664, 2012. 